\title{
Control Beliefs and Risk for Death, Stroke and Myocardial Infarction in Middle-aged and Older Adults: An Observational Study
}

\author{
Wei Duan-Porter, MD, PhD ${ }^{1,2}$, Susan Nicole Hastings, MD, MHSc ${ }^{1,2,3,4}$, Brian Neelon, $P h D^{5}$, and \\ Courtney Harold Van Houtven, MSc, PhD ${ }^{1,2,4}$
}

${ }^{1}$ Health Services Research and Development, Durham VA Medical Center, Durham, NC, USA; ${ }^{2}$ Department of Medicine, Duke University Medical Center, Durham, NC, USA; ${ }^{3}$ Geriatrics Research, Education and Clinical Center, Durham VA Medical Center, Durham, NC, USA; ${ }^{4}$ Duke University Center for the Study of Aging and Human Development, Durham, NC, USA; ${ }^{5}$ Department of Public Health Sciences, Medical University of South Carolina, Charleston, SC, USA.

BACKGROUND: Chronic health conditions account for the largest proportion of illness-related mortality and morbidity as well as most of healthcare spending in the USA. Control beliefs may be important for outcomes in individuals with chronic illness.

OBJECTIVE: To determine whether control beliefs are associated with the risk for death, incident stroke and incident myocardial infarction (MI), particularly for individuals with diabetes mellitus (DM) and/or hypertension. DESIGN: Retrospective cohort study.

PARTICIPANTS: A total of 5,662 respondents to the Health and Retirement Study with baseline health, demographic and psychological data in 2006, with no history of previous stroke or MI.

MAIN MEASURES: Perceived global control, measured as two dimensions-“constraints" and "mastery"-and health-specific control were self-reported. Event-free survival was measured in years, where "event" was the composite of death, incident stroke and MI. Year of stroke or MI was self-reported; year of death was obtained from respondents' family.

KEY RESULTS: Mean baseline age was 66.2 years; 994 (16.7\%) had DM and 3,023 (53.4\%) hypertension. Overall, 173 (3.1\%) suffered incident strokes, 129 (2.3\%) had incident MI, and 465 (8.2\%) died. There were no significant interactions between control beliefs and baseline DM or hypertension in predicting event-free survival. Elevated adjusted hazard ratios (HRs) were associated with DM (1.33, $95 \%$ CI 1.07-1.67), hypertension (1.31, $95 \%$ CI 1.07-1.61) and perceived constraints in the third (1.55, $95 \%$ CI 1.12-2.15) and fourth quartiles (1.61, $95 \% \mathrm{CI}$ 1.14-2.26). Health-specific control scores in the third (HR 0.78, $95 \%$ CI 0.59-1.03) and fourth quartiles (HR 0.70, $95 \%$ CI 0.53-0.92) were protective, but only the latter category had a statistically significant decreased risk. Combined high perceived constraints and low healthspecific control had the highest risk (HR 1.93, $95 \% \mathrm{CI}$ 1.41-2.64).

Electronic supplementary material The online version of this article (doi:10.1007/s11606-015-3275-9) contains supplementary material, which is available to authorized users.

Received November 4, 2014

Revised February 5, 2015

Accepted February 20, 2015

Published online March 20, 2015
CONCLUSIONS: Control beliefs were not associated with differential risk for those with DM and/or hypertension, but they predicted significant differences in event-free survival for the general cohort.

KEY WORDS: control beliefs; mortality; cardiovascular risk.

J Gen Intern Med 30(8):1156-63

DOI: $10.1007 /$ s11606-015-3275-9

(C) Society of General Internal Medicine 2015

\section{BACKGROUND}

In the USA, chronic health conditions account for the largest proportion of illness-related mortality and morbidity ${ }^{1}$ and most of the healthcare spending ( $\$ 2.3$ trillion or $84 \%$ of national expenditures in 2011). ${ }^{2}$ In order to improve outcomes for those with chronic illness, the Chronic Care Model emphasizes the patient's role in developing treatment plans that are flexible, personalized and evidence-based. ${ }^{3-5}$ However, in addition to high self-care demands associated with a single condition such as diabetes mellitus (DM), ${ }^{6}$ many patients need to coordinate treatments and recommendations for multiple diagnoses. ${ }^{7}$ Given the complexity of medical and behavioral recommendations faced by patients, there has been significant interest in determining which psychological factors promote improved health outcomes. ${ }^{8-10}$

Control beliefs have been among the psychological factors proposed to be important for health outcomes. ${ }^{8-13}$ Perceived control refers to an individual's belief in his/her ability to impact events ${ }^{14}$ and range from global beliefs ${ }^{11}$ to perceptions specific for medical conditions or tasks (e.g., scales for $\mathrm{DM}^{15}$ and hypertension $\left.{ }^{16}\right)$. Some have argued that such specific control beliefs are more relevant for health outcomes, ${ }^{10,13}$ while others have suggested that global control beliefs can impact overall health in adulthood. ${ }^{17-19}$

In order to address the relevance of control beliefs for those who are dealing with the complexity of chronic illness management, we focus on the association between control beliefs and long-term health outcomes among individuals with DM and/or hypertension. Both of these conditions are highly prevalent in the US and contribute significantly to the national burden of cardiovascular morbidity and mortality. ${ }^{20}$ Previous 
studies of those with DM and hypertension indicated that control beliefs may impact clinical outcomes and behavioral change, but only short-term outcomes were evaluated (e.g., dietary adherence, blood pressure and glycemic control). ${ }^{8,9,21-}$

${ }^{24}$ We found no investigations addressing the impact of control beliefs on the long-term risk for major cardiovascular events and mortality in DM and hypertension.

In this study, we used data from a large representative survey of middle-aged and older adults in the US to investigate whether control beliefs are associated with risk for death, incident stroke and incident myocardial infarction (MI). Our first goal was to examine whether variation in control beliefs was particularly relevant for those with DM and hypertension compared to those without these conditions. Next, we evaluated the impact of control beliefs on outcomes in the general cohort. Finally, we explored the association of certain combinations of global and health-specific perceived control with survival and cardiovascular morbidity.

\section{METHODS}

\section{Setting and Design}

Data were drawn from the Health and Retirement Study (HRS), an ongoing observational study of middle-aged and older Americans; HRS participants include representative samples of those born during 1924-1959, as well as their spouses/partners. ${ }^{25,26}$ Since 1992, data have been collected through biennial interviews and self-administered surveys. The Participant Lifestyle Questionnaire includes items on psychosocial factors, such as personality traits, control beliefs and social support. ${ }^{27}$ In 2006 , this psychosocial questionnaire was given to a randomly selected group of HRS participants (roughly $50 \%$ of the total cohort).

\section{Participants}

Eligibility criteria included participation in the 2006 HRS wave and no reported history of previous stroke or MI (Fig. 1). Additional exclusion criteria included incomplete or ambiguous data for diagnosis of DM and/or hypertension $(n=254)$, lack of follow-up survey data $(n=358)$ and baseline age younger than 30 or younger than 30 at time of diabetes diagnosis $(n=78)$. We excluded those who were diagnosed with DM before age 30 in order to focus our analysis on type II DM, as type I DM affects younger individuals and is associated with differences in recommended treatments. ${ }^{28,29}$ Among the 13,877 individuals fulfilling the selection criteria, 6,587 were eligible for the psychosocial questionnaire in 2006 but 925 did not respond (or responded via proxy).

This study was approved by the Institutional Review Board of the Durham VA Medical Center.

\section{Measures}

Outcome Measures. Our primary outcome was event-free survival in years, where an "event" was defined as the composite of death (from any cause), incident stroke or incident MI. For each individual, we determined whether any outcome occurred during the follow-up period (2006-2011). For each outcome, we used year of event or length of follow-up without an event (follow-up period calculated as the difference between year of last available survey and year of baseline interview). Year of death was defined using exit interviews with surviving family members. For incident stroke, we looked for affirmative responses to: "Has a doctor ever told you that you had a stroke?" and used self-reported year of stroke to calculate the time to event. We censored individuals who answered "possible stroke" or had invalid or missing data for year of stroke. We employed a similar algorithm to calculate time to first MI. In defining the composite outcome, we used time until first stroke or MI, if either occurred before death, or censored participants at the earliest time when they were censored for individual outcomes.

Control Belief Variables. We used three variables to assess control beliefs: perceived constraints, perceived mastery and health-specific control. Perceived constraints and mastery refer to two dimensions of global control beliefs, indicating perceived external restrictions and personal competence, respectively. ${ }^{11,12,14,27}$ Perceived constraints scores were the mean of responses on a Likert scale $(1=$ strongly disagree, $2=$ somewhat disagree, $3=$ slightly disagree, $4=$ slightly agree, $5=$ somewhat agree, $6=$ strongly agree) to five statements that described lack of control (Supplemental Table 1). Perceived mastery was the mean of responses (on the same Likert scale) to five statements indicating confidence in one's ability to act (Supplemental Table 1). Previous work showed Cronbach alphas of 0.86 and 0.89 for perceived constraints and mastery scales, respectively. ${ }^{30,31}$ Health-specific control scores were numerical responses to a single question: "Using a 0 to 10 scale where 0 means 'no control at all' and 10 means 'very much control,' how would you rate the amount of control you have over your health these days?"

Because both global and health-specific control variables showed highly skewed distributions, we were concerned about nonlinear effects. Thus, we categorized scores into quartiles to improve interpretation of relationships between control beliefs and health risk. In order to investigate the combined effects of global and domain-specific control beliefs, we performed separate modeling for four psychological groups with either "low" or "high" perceived constraints and health-specific control, based on a median split for each variable.

Main Biomedical Predictors. For presence of DM and hypertension, we used affirmative responses to two questions addressing these conditions, both beginning with "Has a doctor ever told you that..."32 Age at diagnosis and duration of DM were computed from self-reported year of diagnosis and baseline age. Respondents also answered questions about management of their medical conditions.

Covariates. Baseline covariates included demographic factors, other health conditions, behaviors, functional status and other 


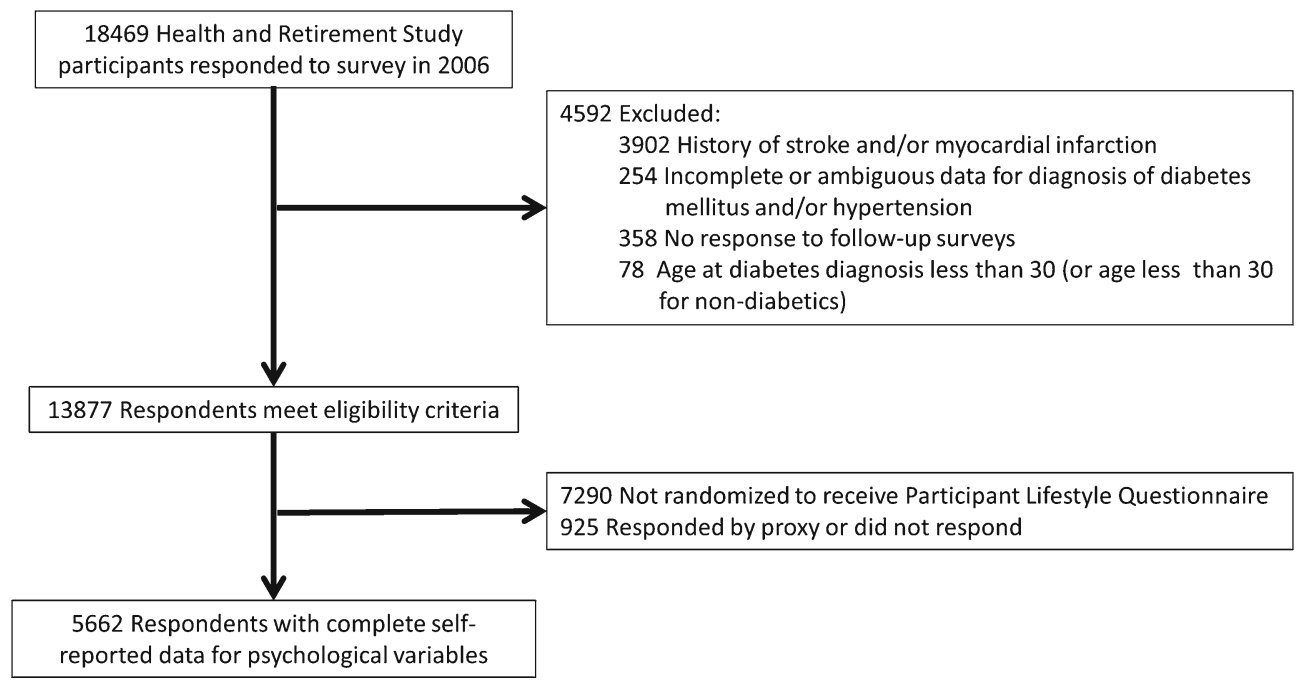

Figure 1 Selection of study sample from Health and Retirement Study participants

psychological variables. We used binary indicators for selfreported heart disease, lung disease, cancer ("excluding minor skin cancer"), psychological problems, arthritis, current smoking and participation in vigorous activity more than once a week. Functional status variables included a binary indicator of whether respondents had memory problems and count variables of the number of basic or instrumental activities of daily living (ADLs or IADLs, respectively) with which respondents had some difficulty. Psychological covariates included scores on the eight-question Centers of Epidemiologic Studies Depression Scale (CESD8) ${ }^{33}$ and positive and negative affect scales. Positive and negative affect scores were each calculated as the mean of reverse coded responses to six questions (response options were $1=$ all of the time to $5=$ none of the time). ${ }^{34}$ See Supplemental Table 1 for detailed information on survey questions for functional limitations, CESD8 and affect scales.

\section{Statistical Analysis}

To address the differential effects of control beliefs in those with $\mathrm{DM}$ and/or hypertension, we used a discrete time-toevent analysis ${ }^{35}$ with a complementary log-log link to model event-free survival from the composite of death, incident stroke and MI. We first tested for interaction effects between control beliefs and DM and/or hypertension in basic models including only main predictors, before adjustment for all covariates described above. Here, we present hazard ratios (HRs) from the basic and fully adjusted models with only main effects, along with predicted accumulated hazard curves for the composite outcome from the full model.

To examine the combined effects of global and domainspecific control beliefs, we conducted similar discrete time-toevent modeling as noted above, but instead classified respondents into one of four psychological groups based on "low" or "high" perceived constraints and health-specific control. We used perceived constraints and health-specific control to define these groups because they were each significantly associated with risk for the outcome, whereas perceived mastery was not. Thus, perceived mastery was retained in these models but not included in our construction of the four psychological groups. In addition to reporting adjusted hazard ratios, we also calculated the total number of events and event rates per 1,000 person-years for each group.

There were small proportions of missing data for covariates, with the highest being $5 \%$ missingness for CESD 8 scores. We used multiple imputations by chained equations ${ }^{36}$ to generate pooled parameter estimates based on 25 imputed data sets, under a missingness at random assumption. To assess for multicollinearity, we examined covariate correlations and variance inflation factors. We also assured that all model parameters were estimable with low standard errors. All analyses and graphs were generated using $\mathrm{R}$ version 3.0.2.

\section{RESULTS}

Baseline characteristics and number of events are provided in Table 1. Almost one in five reported having DM and half had hypertension; most adults with diabetes were taking oral medications and nearly a fifth used insulin. Almost everyone with DM or hypertension indicated that their conditions were well controlled. Most participants had at least a high school degree, nearly all had health insurance, and most reported no difficulty with any ADL or IADL. Overall, respondents reported low perceived constraints, high perceived mastery and high healthspecific control.

Among HRS participants who met our inclusion criteria, including being eligible for the psychosocial survey in 2006, 925 had missing responses for the psychological variables of interest. Compared with the analysis cohort (Supplemental Table 2), individuals with missing psychological data included more African Americans (26\%) and Hispanics (17\%), and a lower proportion had at least a high school degree (63\%). The 
Table 1 Baseline Characteristics and Event Rates for the Study Sample $(n=5,662)$

\begin{tabular}{|c|c|}
\hline \multicolumn{2}{|l|}{ Sociodemographic characteristics } \\
\hline Age, mean (SD), years & $66.2(10.4)$ \\
\hline Female, n $(\%)$ & $3,462(61.1)$ \\
\hline \multicolumn{2}{|l|}{ Race, n $(\%)$} \\
\hline White & $4,815(85.0)$ \\
\hline Black & $694(12.3)$ \\
\hline Other & $153(2.7)$ \\
\hline Hispanic, n (\%) & 448 (7.9) \\
\hline Married, n (\%) & $3,737(66.0)$ \\
\hline High school degree or above, n (\%) & $4,521(79.8)$ \\
\hline Veteran, $\mathrm{n}(\%)$ & $1,198(21.2)$ \\
\hline Working for pay, n (\%) & $2,373(41.9)$ \\
\hline \multicolumn{2}{|l|}{ Total household income*, n (\%) } \\
\hline 1st quartile & $1,267(22.4)$ \\
\hline 2nd quartile & $1,378(24.3)$ \\
\hline 3rd quartile & $1,449(25.6)$ \\
\hline 4th quartile & $1,568(27.7)$ \\
\hline Any insurance, n (\%) & $5,352(94.5)$ \\
\hline \multicolumn{2}{|l|}{ Biomedical conditions } \\
\hline Diabetes mellitus, n (\%) & $994(16.7)$ \\
\hline Duration of diabetes, mean (SD), years & $8.59(7.57)$ \\
\hline Age at diabetes diagnosis, mean (SD), years & $58.73(10.63)$ \\
\hline Diabetes well controlled, $\mathrm{n}(\%)^{\dagger}$ & $877(92.9)$ \\
\hline Taking oral diabetes medications, $\mathrm{n}(\%)^{\dagger}$ & $701(74.3)$ \\
\hline Using insulin, $\mathrm{n}(\%)^{\dagger}$ & $168(17.8)$ \\
\hline Diabetic nephropathy, n $(\%)^{\dagger}$ & $69(7.3)$ \\
\hline Hypertension, $\mathrm{n}(\%)$ & $3,023(53.4)$ \\
\hline Hypertension well controlled, $\mathrm{n}(\%)^{\dagger}$ & $2,905(96.1)$ \\
\hline Taking oral hypertension medications, $\mathrm{n}(\%)^{\dagger}$ & $2,689(89.0)$ \\
\hline Heart disease, n (\%) & $833(14.7)$ \\
\hline Cancer, n (\%) & 774 (13.7) \\
\hline Lung disease, $\mathrm{n}(\%)$ & $491(8.7)$ \\
\hline Arthritis, n (\%) & $3,259(57.6)$ \\
\hline \multicolumn{2}{|l|}{ Psychological characteristics } \\
\hline Constraints, median $(\mathrm{Q} 1, \mathrm{Q} 3)$, range $1-6$ & $1.8(1.2,2.8)$ \\
\hline Mastery, median (Q1,Q3), range 1-6 & $5.0(4.2,5.6)$ \\
\hline Health-specific control, median (Q1,Q3), range $0-10$ & $8(6,9)$ \\
\hline Positive affect, mean (SD), range $1-5$ & $3.60(0.68)$ \\
\hline Negative affect, mean (SD), range $1-5$ & $1.60(0.64)$ \\
\hline Psychiatric problems, n (\%) & $843(14.9)$ \\
\hline CESD8, mean (SD), range $0-8$ & $1.32(1.87)$ \\
\hline \multicolumn{2}{|l|}{ Functional characteristics } \\
\hline Problems with memory, n (\%) & $97(1.7)$ \\
\hline Number of ADLs ${ }^{*}$ with difficulty, mean (SD), & $0.20(0.65)$ \\
\hline range $0-5$ & \\
\hline $\begin{array}{l}\text { Number of IADLs }{ }^{\ddagger} \text { with difficulty, mean (SD), } \\
\text { range } 0-5\end{array}$ & $0.15(0.56)$ \\
\hline \multicolumn{2}{|l|}{ Health behaviors } \\
\hline Vigorous activity more than once per week, n (\%) & $1,404(24.8)$ \\
\hline Smoking now, n (\%) & $767(13.5)$ \\
\hline \multirow{2}{*}{\multicolumn{2}{|c|}{ Events }} \\
\hline & \\
\hline Composite outcome ${ }^{\S}, \mathrm{n}(\%)$ & $483(8.5)$ \\
\hline Deaths, n (\%) & $465(8.2)$ \\
\hline Incident strokes, n (\%) & $173(3.1)$ \\
\hline Incident myocardial infarction, $\mathrm{n}(\%)$ & $129(2.3)$ \\
\hline
\end{tabular}

*Quartiles assigned based on distribution of incomes from all 13,877 individuals who met all selection criteria aside from having psychological data in 2006

${ }^{t}$ Proportion of all those with a relevant health condition

${ }^{*}$ Count of the number of activities of daily living (ADLs) or instrumental activities of daily living (IADLs) for which respondent answered as having at least some difficulty

${ }^{s}$ Composite outcome includes incident stroke or myocardial infarction and death

income distribution was also skewed toward the lower quartiles (e.g., $34 \%$ in lowest quartile). There were no differences in health conditions or functional impairments, except for increased reports of memory problems $(6 \%)$.

In evaluating the impact of control beliefs on event-free survival, we found no statistically significant interaction effects between control beliefs and DM and/or hypertension. However, we identified significant main effects associated with perceived constraints and health-specific control (Table 2). In the basic model, the greatest hazards were associated with perceived constraints scores in the fourth quartile (HR 2.15, 1.57-3.00 95\% CI), while DM or hypertension was associated with relatively less risk (HR 1.34 and 1.59 , respectively). In the fully adjusted model, the effect for perceived constraints was smaller but remained statistically significant and meaningful (HR 1.61, 1.14-2.26 95\% CI). In contrast, increasing scores for health-specific control were associated with significantly decreased risk in both the basic and full models, although only scores in the fourth quartile were significant in the fully adjusted model (HR $0.70,0.53-0.9295 \% \mathrm{CI})$. Higher scores for perceived mastery were also associated with decreased risk in the basic model, but these effects did not remain significant after full adjustment (Table 2).

In order to understand the combined effect of global and health-specific control beliefs, we compared overall event-free survival for those with "low" (scores below the median) or "high" (scores at or greater than the median) perceived constraints and health-specific control. Using low perceived constraints and high health-specific control as the reference group, all other groups had significantly increased risk in the fully adjusted model (Table 3); those with high perceived constraints and low health-specific control had the greatest risk (HR 1.93, 1.41-2.64 $95 \% \mathrm{CI}$ ), with predicted cumulative hazards of nearly $15 \%$ by the end of follow-up (Fig. 2). There were also consistent differences in event rates (Table 3). Of note, there was moderate inverse correlation between perceived constraints and health-specific control (Pearson correlation coefficient $-0.34, \mathrm{p}<0.001)$, leading to relatively fewer respondents who were categorized as both "low" and "high" for these variables.

\section{DISCUSSION}

In this longitudinal study of older and middle-aged American adults, perceived constraints and health-specific control were significantly associated with risk for a composite of incident stroke, MI and death, but there were no significant interaction effects between control beliefs and DM and/or hypertension. Thus, for both those with and without these chronic illnesses, control beliefs had the same association with event-free survival. Higher perceived constraints predicted increased risk and higher health-specific control was associated with decreased risk; having the combination of high-risk perceptions for both factors (i.e., high perceived constraints and low health-specific control) was associated with the highest cumulative hazards. All of these effects remained significant after accounting for other chronic health conditions, sociodemographic variables, functional impairments and other psychological factors, including depression symptoms. In contrast, 
Table 2 Hazard Ratios for the Composite Outcome in the Basic and Fully Adjusted Survival Models

\begin{tabular}{|c|c|c|c|c|}
\hline & \multicolumn{2}{|l|}{ Basic model* } & \multicolumn{2}{|l|}{ Full model $^{\dagger}$} \\
\hline & Hazard ratio $(95 \% \mathrm{CI})$ & P-value & Hazard ratio $(95 \% \mathrm{CI})$ & P-value \\
\hline \multicolumn{5}{|l|}{ Biomedical predictors } \\
\hline No diabetes mellitus or hypertension & 1 & - & 1 & - \\
\hline Diabetes mellitus & $1.34(1.08-1.65)$ & 0.009 & $1.33(1.07-1.67)$ & 0.009 \\
\hline Hypertension & $1.59(1.31-1.93)$ & $\mathrm{p}<0.001$ & $1.31(1.07-1.61)$ & 0.008 \\
\hline \multicolumn{5}{|l|}{ Psychological predictors } \\
\hline \multicolumn{5}{|l|}{ Perceived constraints } \\
\hline 1st Quartile & 1 & - & 1 & - \\
\hline 2nd Quartile & $1.15(0.81-1.63)$ & 0.37 & $1.09(0.76-1.55)$ & 0.63 \\
\hline 3rd Quartile & $1.70(1.24-2.33)$ & $\mathrm{p}<0.001$ & $1.55(1.12-2.15)$ & 0.007 \\
\hline 4th Quartile & $2.15(1.57-3.00)$ & $\mathrm{p}<0.001$ & $1.61(1.14-2.26)$ & 0.005 \\
\hline \multicolumn{5}{|l|}{ Perceived mastery } \\
\hline 1st Quartile & 1 & - & 1 & - \\
\hline 2nd Quartile & $0.72(0.56-0.93)$ & 0.009 & $0.86(0.66-1.12)$ & 0.25 \\
\hline 3rd Quartile & $0.74(0.57-0.95)$ & 0.02 & $0.89(0.67-1.16)$ & 0.37 \\
\hline 4th Quartile & $0.81(0.61-1.07)$ & 0.13 & $0.99(0.73-1.34)$ & 0.95 \\
\hline \multicolumn{5}{|l|}{ Health-specific control } \\
\hline 1st Quartile & 1 & - & 1 & - \\
\hline 2nd Quartile & $0.72(0.56-0.92)$ & 0.008 & $0.82(0.63-1.06)$ & 0.13 \\
\hline 3rd Quartile & $0.66(0.49-0.83)$ & 0.001 & $0.78(0.59-1.03)$ & 0.07 \\
\hline 4th Quartile & $0.56(0.43-0.73)$ & $\mathrm{p}<0.001$ & $0.70(0.53-0.92)$ & 0.01 \\
\hline
\end{tabular}

*Basic model includes diabetes mellitus, hypertension, perceived constraints, perceived mastery and health-specific control

${ }^{\dagger}$ In addition to variables in the basic model, the full model includes self-reported heart disease, lung disease, cancer, psychological problems, arthritis, memory difficulties, baseline smoking, vigorous activity more than once a week, difficulty with activities of daily living (ADLs) or instrumental activities of daily living (IADLs), score on the 8-question Centers of Epidemiologic Studies Depression Scale (CESD8), and scores for positive and negative affect; see Methods for full variable definitions

perceived mastery was not significantly associated with risk after full adjustment.

Our study is the first to evaluate associations between control beliefs and long-term health outcomes for those with clear self-management needs, namely individuals with DM and/or hypertension. We proposed that control beliefs may be relevant in this population, based on previous work showing that condition or task-specific control beliefs were associated with health behaviors and physiologic markers. ${ }^{8,9,21-24}$ Some evidence also indicated general control beliefs were associated with differences in illness-specific control beliefs. ${ }^{37}$ It is possible that we did not detect interaction effects because general control beliefs have diverse effects on health, beyond self-care behaviors solely associated with DM and hypertension. Perhaps, control beliefs impact management of other important cardiovascular risk factors, such as hyperlipidemia.
Some works also suggest that positive psychological perceptions are associated with increased longevity, due to effects on health behaviors and reductions in the negative physiologic consequences of chronic stress or anxiety. 9,38,39 Additionally, control beliefs may differentially affect those who have more difficulty managing their chronic medical conditions than was found in our HRS cohort. Although the high levels of selfreported DM and hypertension control likely reflect a certain degree of subjective reporter bias, our findings support that HRS participants with these conditions are generally under good control; DM and hypertension were associated with only moderate levels of increased risk for mortality and cardiovascular events compared with hazard ratios previously reported for uncontrolled disease. ${ }^{20,40-42}$ Other studies evaluating a subset of HRS respondents also found similar moderately increased risks for DM and hypertension. ${ }^{43,44}$

Table 3 Composite and Individual Outcomes by Psychological Groups Based on Level of Perceived Constraints and Health-specific Control

\begin{tabular}{|c|c|c|c|c|}
\hline \multirow{2}{*}{$\begin{array}{l}\text { Perceived constraints* } \\
\text { Health-specific control* }\end{array}$} & \multicolumn{2}{|l|}{ Low } & \multicolumn{2}{|l|}{ High } \\
\hline & High $(n=1,859)$ & Low $(n=680)$ & High $(n=1,470)$ & Low $(n=1,653)$ \\
\hline \multicolumn{5}{|l|}{ Composite outcome } \\
\hline Adjusted ${ }^{\dagger}$ hazard ratios $(95 \% \mathrm{CI})$ & 1 & $1.44(1.00-2.07)$ & $1.65(1.22-2.23)$ & $1.93(1.41-2.64)$ \\
\hline Adjusted ${ }^{\dagger} p$-value & - & 0.05 & $<0.001$ & $<0.001$ \\
\hline Events, n (rate) & $82(11.3)$ & $51(19.6)$ & $129(23.3)$ & $216(36.4)$ \\
\hline \multicolumn{5}{|l|}{ Individual outcomes } \\
\hline Incident stroke, $\mathrm{n}$ (rate) & $32(4.4)$ & $21(7.9)$ & $55(9.7)$ & $65(10.8)$ \\
\hline Incident heart attack, $\mathrm{n}$ (rate) & $22(3.0)$ & $14(5.3)$ & $41(7.3)$ & $47(7.8)$ \\
\hline Death, n (rate) & $85(9.4)$ & $48(14.6)$ & $116(16.4)$ & $216(28.2)$ \\
\hline
\end{tabular}

*Low and high were determined by whether scores were below or at least equal to the median, respectively

${ }^{\prime}$ Discrete time-to-event model included psychological groups (based on perceived constraints and health-specific control), main biomedical predictors (diabetes and hypertension), perceived mastery (in quartiles), self-reported heart disease, lung disease, cancer, psychological problems, arthritis, memory difficulties, baseline smoking, vigorous activity more than once a week, difficulty with activities of daily living (ADLs) or instrumental activities of daily living (IADLs), score on the 8-question Centers of Epidemiologic Studies Depression Scale (CESD8), and scores for positive and negative affect; see Methods for full variable definitions

${ }^{7}$ Rate calculated as number of events per 1,000 person-years of follow-up 

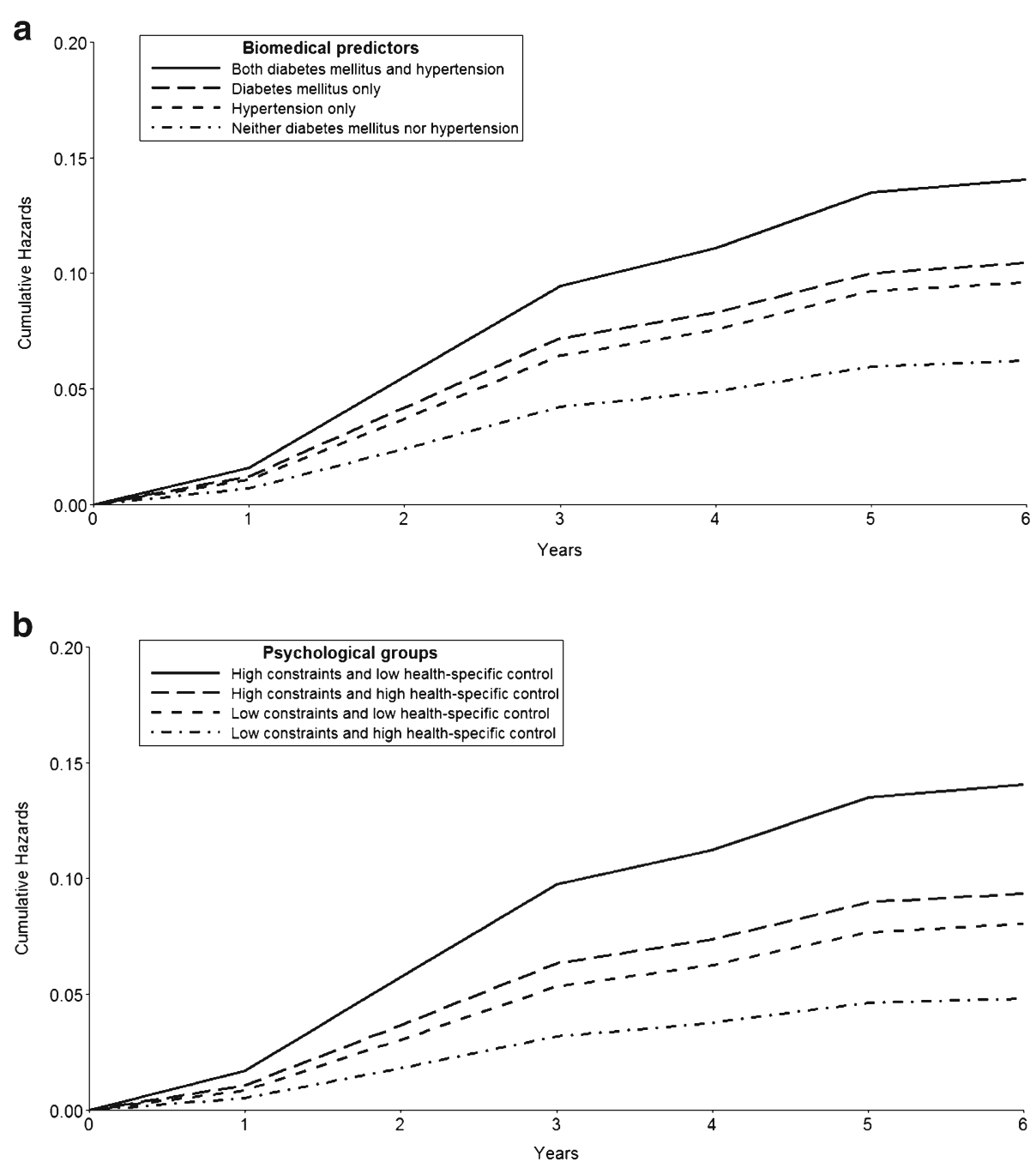

Figure 2 Adjusted cumulative hazard curves for composite outcome among groups differing in main biomedical and psychological predictors. (A) Predicted cumulative hazard curves for groups based on diagnoses of diabetes mellitus and hypertension, using the fully adjusted discretetime model. (B) Predicted cumulative hazard curves for groups based on perceived constraints and health-specific control scores, using the fully adjusted discrete-time model. Perceived constraints and health-specific control scores below the median were categorized as "low," while scores at or above the median were designated as "high"

While we did not find significant interaction effects in our study, we have demonstrated important associations of control beliefs with long-term clinical outcomes in the general cohort. Previous work evaluating the role of control beliefs in health and survival did not show robust effects after adjustment for factors such as depressive symptoms and often treated health as either a single self-reported rating or a count of all conditions. ${ }^{17-19}$ We addressed each chronic illness as an independent factor, adjusted for a rich set of socioeconomic characteristics, and accounted for multiple other psychological factors. Interestingly, perceived mastery was not significantly associated with event-free survival, indicating that perceived constraints and health-specific control are more closely tied to health outcomes. Past studies have also shown that "negative" control perceptions (i.e., constraints) may be more relevant than "positive" beliefs (i.e., mastery) for health outcomes, although they did not offer explanations for this difference. $^{12,45} \mathrm{We}$ were unable to discern in our HRS data set whether, for example, respondents make more realistic assessments of constraints compared with perceived mastery or individuals are more affected by negative beliefs in healthrelated behavior. However, as a whole, our study extends and confirms the importance of control beliefs for health and mortality in the general population.

Our results lead to several possibilities for how control beliefs may affect medical management and preventative care. First, differences in control beliefs can expand the definition of high-risk groups, which are usually based on medical complexity and/or functional impairments ${ }^{46-49}$; some have argued that such high-risk groups should be targeted for intensive (and often expensive) care management, ${ }^{50}$ while others propose that outcomes in these groups are more relevant for payfor-performance incentives. ${ }^{51}$ Even in our relatively healthy and non-impaired HRS sample, variation in control beliefs was associated with risk for poor outcomes. Second, an individual's control beliefs may affect long-term response to any 
given intervention, as some work has suggested that interventions work better when the level of choice and engagement corresponds with personal control beliefs. ${ }^{52}$ General control beliefs are also correlated with illness-specific beliefs, ${ }^{37}$ which in turn can predict behavioral changes. ${ }^{22}$ Finally, disparities in general control beliefs could be targeted by future interventions. Most previous work on changing control beliefs has focused on certain tasks and goals, such as confidence in obtaining social support among those with $\mathrm{DM} .^{53}$ In contrast, global control beliefs reflect socioeconomic factors and are fairly stable over a period of years, with a gradual decline after middle or late adulthood. ${ }^{12,54,55}$ However, there may be discontinuous declines in control beliefs at the time of significant health shocks, and such changes may not have been captured by previous work evaluating these beliefs over years. If changes in control beliefs occur during difficult health experiences, efforts to mitigate these effects may be important for long-term health, especially for disadvantaged populations.

There are several limitations to our study. Although a strength of HRS data is that participants are a nationally representative sample of American adults, our HRS cohort had low functional impairment and generally well-controlled medical conditions; it is unclear whether our findings may be as relevant for groups with poorer health and/or greater impairment. Also, HRS participants with missing psychological data included a greater proportion of minorities, had less education and lower income status; these characteristics are all associated with lower global control beliefs. Thus, our findings may have been affected by lack of response from minority participants and those with lower socioeconomic status. We rely on self-reported data for medical diagnoses and health events; compared against medical records, selfreported data are biased toward under-reporting of conditions, ${ }^{56,57}$ whereas self-reports may be more accurate than claims data. ${ }^{58}$ When patient self-reports are compared with information reported by physicians, there is high concordance for DM and somewhat less for hypertension. ${ }^{59}$ Additionally, we treated all covariates as time-invariant, although many of these likely changed with time (e.g., ADL, IADL, depressive symptoms, etc.); the retrospective nature and biennial followup period of HRS surveys limited our ability to account for changing covariates. Also, given the duration of available follow-up, we had insufficient power for separate assessments of risk for stroke and MI, and we could not examine outcomes over a longer period of time. We conducted exploratory analyses on the combined effects of perceived constraints and health-specific control, but further studies are needed to confirm the importance of such psychological groups. Finally, our study is based on observational data, and there remains the possibility of unmeasured confounders, despite our attempts to adjust for conceptually important factors.

Despite the above limitations, our study provides support for the relevance of control beliefs for risk of death and major cardiovascular events. More work is needed to determine how control beliefs may impact patient interactions with the health system and individual responses to clinical interventions. Elucidation of the multifactorial effects associated with variation in control beliefs can improve our ability to determine who will most likely benefit from existing resources, as well as help us develop new ways to support those at risk.

\section{Contributors: None}

Funder/Sponsor: Support for Wei Duan-Porter was provided by grant no. TPP 21-022 from the Department of Veteran Affairs, Office of Academic Affiliations.

\section{Prior Presentations: None}

Conflict of Interest: The authors declare that they do not have a conflict of interest.

Corresponding Author: Wei Duan-Porter, $M D, P h D$; Health Services Research and DevelopmentDurham VA Medical Center, Durham, NC, USA (e-mail: wei.duan-porter@duke.edu).

\section{REFERENCES}

1. US Burden of Disease Collaborators. The state of US health, 1990-2010: burden of diseases, injuries, and risk factors. JAMA. 2013;310(6):591-608.

2. Moses H, Matheson DHM, Dorsey ER, George BP, Sadoff D, Yoshimura S. The anatomy of health care in the United States. JAMA. 2013;310(18): 1947-1963. doi:10.1001/jama.2013.281425.

3. Bodenheimer T, Wagner EH, Grumbach $\mathbf{K}$. Improving primary care for patients with chronic illness. JAMA. 2002;288(14):1775-9.

4. Bodenheimer $\mathbf{T}$, Lorig $\mathbf{K}$, Holman $\mathbf{H}$, Grumbach $\mathbf{K}$. Patient selfmanagement of chronic disease in primary care. JAMA. 2002;288(19):2469-75.

5. Coleman K, Austin BT, Brach C, Wagner EH. Evidence on the Chronic Care Model in the new millennium. Health Aff (Millwood). 2009;28(1):7585. doi:10.1377/hlthaff.28.1.75.

6. AADE7 $7^{\mathrm{TM}}$ - American Association of Diabetes Educators. Available at: http://www.diabeteseducator.org/ProfessionalResources/AADE7/. Accessed February 18, 2015.

7. Boyd CM, Darer J, Boult C, Fried LP, Boult L, Wu AW. Clinical practice guidelines and quality of care for older patients with multiple comorbid diseases: implications for pay for performance. JAMA. 2005;294(6):716724. doi:10.1001/jama.294.6.716.

8. Gherman A, Schnur J, Montgomery G, Sassu R, Veresiu I, David D. How are adherent people more likely to think? A meta-analysis of health beliefs and diabetes self-care. Diabetes Educ. 2011;37(3):392-408. doi:10. $1177 / 0145721711403012$.

9. Celano CM, Beale EE, Moore SV, Wexler DJ, Huffman JC. Positive psychological characteristics in diabetes: a review. Curr Diab Rep. 2013;13(6):917-929. doi:10.1007/s11892-013-0430-8.

10. Schwarzer R, Lippke S, Luszczynska A. Mechanisms of health behavior change in persons with chronic illness or disability: the Health Action Process Approach (HAPA). Rehabil Psychol. 2011;56(3):161-170. doi:10. $1037 / \mathrm{a} 0024509$.

11. Pearlin LI, Schooler C. The structure of coping. J Health Soc Behav. 1978; 19(1):2-21.

12. Lachman ME, Weaver SL. The sense of control as a moderator of social class differences in health and well-being. J Pers Soc Psychol. 1998;74(3):763-73.

13. Bandura A. Health promotion from the perspective of social cognitive theory. Psychol Health. 1998;13(4):623-649. doi:10.1080/ 08870449808407422.

14. Skinner EA. A guide to constructs of control. J Pers Soc Psychol. 1996;71(3):549-570.

15. Tillotson LM, Smith MS. Locus of control, social support, and adherence to the diabetes regimen. Diabetes Educ. 1996;22(2):133-9.

16. Botha KFH, Plessis WFD, Rooyen JMV, Wissing MP. Biopsychosocial determinants of self-management in culturally diverse South African patients with essential hypertension. J Health Psychol. 2002;7(5):519531. doi:10.1177/1359105302007005672. 
17. Infurna FJ, Gerstorf D, Ram N, Schupp J, Wagner GG. Long-term antecedents and outcomes of perceived control. Psychol Aging. 2011;26(3):559-575. doi:10.1037/a0022890.

18. Infurna FJ, Gerstorf D, Zarit SH. Examining dynamic links between perceived control and health: longitudinal evidence for differential effects in midlife and old age. Dev Psychol. 2011;47(1):9-18. doi:10.1037/a0021022.

19. Infurna FJ, Ram N, Gerstorf $\mathbf{D}$. Level and change in perceived control predict 19-year mortality: findings from the Americans' changing lives study. Dev Psychol. 2013;49(10):1833-1847. doi:10.1037/a0031041.

20. Go AS, Mozaffarian D, Roger VL, et al. Heart Disease and Stroke Statistics-2013 Update A Report From the American Heart Association. Circulation. 2013;127(1):e6-e245. doi:10.1161/CIR.0b013e31828124ad.

21. Krichbaum K, Aarestad V, Buethe M. Exploring the connection between self-efficacy and effective diabetes self-management. Diabetes Educ. 2003;29(4):653-62.

22. Hagger MS, Orbell S. A meta-analytic review of the common-sense model of illness representations. Psychol Health. 2003;18(2):141-184. doi:10. 1080/088704403100081321

23. Warren-Findlow J, Seymour RB, Brunner Huber LR. The association between self-efficacy and hypertension self-care activities among African American adults. J Community Health. 2012;37(1):15-24. doi:10.1007/ s10900-011-9410-6.

24. Mansyur CL, Pavlik VN, Hyman DJ, Taylor WC, Goodrick GK. Selfefficacy and barriers to multiple behavior change in low-income African Americans with hypertension. J Behav Med. 2013;36(1):75-85. doi:10. 1007/s10865-012-9403-7.

25. Growing Older in America: The Health and Retirement Study | National Institute on Aging. Available at: http://www.nia.nih.gov/health/publication/growing-older-america-health-and-retirement-study. Accessed February 18,2015

26. Health and Retirement Study. Available at: http://hrsonline.isr.umich. edu/. Accessed February 18, 2015.

27. Smith J, Fisher G, Ryan L, Clarke P, House J, Weir DR. Psychosocial and Lifestyle Questionnaire 2006-2010: Documentation Report. Ann Arbor: Survey Research Center, University of Michigan; 2013.

28. American Diabetes Association. 2. Classification and diagnosis of diabetes Diabetes Care. 2015;38(Supplement_1):S8-S16. doi:10.2337/dc15-S005.

29. American Diabetes Association. 7. Approaches to glycemic treatment. Diabetes Care. 2015;38(Supplement 1):S41-S48. doi:10.2337/dc15-S010.

30. Ward MM. Sense of control and sociodemographic differences in selfreported health in older adults. Qual Life Res. 2012;21(9):1509-1518. doi:10.1007/s11136-011-0068-4.

31. Ward MM. Sense of control and self-reported health in a population-based sample of older Americans: assessment of potential confounding by affect, personality, and social support. Int J Behav Med. 2013;20(1):140-147. doi:10.1007/s12529-011-9218-x.

32. Fisher G, Faul JD, Weir DR, Wallace RB. Documentation of Chronic Disease Measures in the Health and Retirement Study (HRS/AHEAD). Ann Arbor: Survey Research Center, University of Michigan; 2005.

33. Steffick DE. Documentation of Affective Functioning Measures in the Health and Retirement Study. Ann Arbor: Survey Research Center, University of Michigan; 2000.

34. Ward MM. Sense of control and self-reported health in a population-based sample of older Americans: assessment of potential confounding by affect, personality, and social support. Int J Behav Med. 2013;20(1):140-147. doi:10.1007/s12529-011-9218-x

35. Singer JD, Willett JB. It's about time: using discrete-time surviva analysis to study duration and the timing of events. J Educ Stat. 1993;18(2): 155-195. doi:10.3102/10769986018002155.

36. van Buuren S, Groothuis-Oudshoom K. MICE: multivariate imputation by chained equations in R. J Stat Softw. 2011;45(3):1-67.

37. Schüz B, Wurm S, Warner LM, Ziegelmann JP. Self-efficacy and multiple illness representations in older adults: a multilevel approach. Psychol Health. 2012;27(1):13-29. doi:10.1080/08870446.2010.541908.

38. Pitkala KH, Laakkonen ML, Strandberg TE, Tilvis RS. Positive life orientation as a predictor of 10-year outcome in an aged population. J Clin Epidemiol. 2004;57(4):409-414. doi:10.1016/j.jclinepi.2003.07.013.

39. Boyle PA, Barnes LL, Buchman AS, Bennett DA. Purpose in life is associated with mortality among community-dwelling older persons.
Psychosom Med. 2009;71(5):574-579. doi:10.1097/PSY. Ob013e3181a5a7c0.

40. Franco OH, Peeters A, Bonneux L, de Laet C. Blood pressure in adulthood and life expectancy with cardiovascular disease in men and women: life course analysis. Hypertension. 2005;46(2):280-286. doi:10. 1161/01.HYP.0000173433.67426.9b.

41. Stratton IM, Adler AI, Neil HA, et al. Association of glycaemia with macrovascular and microvascular complications of type 2 diabetes (UKPDS 35): prospective observational study. BMJ. 2000;321(7258):405-12.

42. Adler AI, Stratton IM, Neil HA, et al. Association of systolic blood pressure with macrovascular and microvascular complications of type 2 diabetes (UKPDS 36): prospective observational study. BMJ. 2000;321(7258):412-9.

43. Wolinsky FD, Bentler SE, Cook EA, et al. A 12-year prospective study of stroke risk in older Medicare beneficiaries. BMC Geriatr. 2009;9:17. doi:10. 1186/1471-2318-9-17.

44. Wolinsky FD, Bentler SE, Liu L, et al. Prior hospitalization and the risk of heart attack in older adults: a 12-year prospective study of Medicare beneficiaries. J Gerontol A Biol Sci Med Sci. 2010;65(7):769-777. doi:10. 1093/gerona/glq003.

45. Surgenor LJ, Horn J, Hudson SM, Lunt H, Tennent J. Metabolic control and psychological sense of control in women with diabetes mellitus. J Psychosom Res. 2000;49(4):267-73.

46. Fortin M, Hudon C, Dubois M-F, Almirall J, Lapointe L, Soubhi H. Comparative assessment of three different indices of multimorbidity for studies on health-related quality of life. Health Qual Life Outcomes. 2005;3:74. doi:10.1186/1477-7525-3-74.

47. Carey EC, Walter LC, Lindquist $\mathbf{K}$, Covinsky KE. Development and validation of a functional morbidity index to predict mortality in community-dwelling elders. J Gen Intern Med. 2004;19(10):1027-1033. doi:10.1111/j.1525-1497.2004.40016.x.

48. Flottemesch TJ, Anderson LH, Solberg LI, Fontaine P, Asche SE. Patient-centered medical home cost reductions limited to complex patients. Am J Manag Care. 2012;18(11):677-86.

49. Higgins S, Chawla R, Colombo C, Snyder R, Nigam S. Medical homes and cost and utilization among high-risk patients. Am J Manag Care. 2014;20(3):e61-e71.

50. Schwenk TL. The patient-centered medical home: one size does not fit all. JAMA. 2014;311(8):802-803. doi:10.1001/jama.2014.352.

51. McKethan A, Jha AK. Designing smarter pay-for-performance programs. JAMA. 2014;312(24):2617-2618. doi:10.1001/jama.2014.15398.

52. Rodin J. Aging and health: effects of the sense of control. Science 1986;233(4770): 1271-6.

53. Anderson RM, Funnell MM, Butler PM, Arnold MS, Fitzgerald JT, Feste CC. Patient empowerment. Results of a randomized controlled trial. Diabetes Care. 1995; 18(7):943-9.

54. Pudrovska T, Schieman S, Pearlin LI, Nguyen K. The sense of mastery as a mediator and moderator in the association between economic hardship and health in late life. J Aging Health. 2005;17(5):634-660. doi:10.1177/ 0898264305279874.

55. Mirowsky J, Ross CE. Life Course Trajectories of Perceived Control and Their Relationship to Education. Am J Sociol. 2007;112(5):1339-1382. doi: 10.1086/509519.

56. Harlow SD, Linet MS. Agreement between questionnaire data and medical records. The evidence for accuracy of recall. Am J Epidemiol. 1989;129(2):233-48.

57. Okura Y, Urban LH, Mahoney DW, Jacobsen S.J, Rodeheffer RJ. Agreement between self-report questionnaires and medical record data was substantial for diabetes, hypertension, myocardial infarction and stroke but not for heart failure. J Clin Epidemiol. 2004;57(10):10961103. doi:10.1016/j.jclinepi.2004.04.005.

58. Joseph Sakshaug, David Weir, Lauren Hersch Nicholas. Validating Diabetes Disease Status in Claims and Survey Data. Ottawa, Ontario, Canada: Statistics Canada's 2010 International Methodology Symposium; 2011:400-5

59. Hansen H, Schäfer I, Schön G, et al. Agreement between self-reported and general practitioner-reported chronic conditions among multimorbid patients in primary care-results of the MultiCare Cohort Study. BMC Fam Pract. 2014;15:39. doi:10.1186/1471-2296-15-39. 